\title{
Reninoma: The Importance of Renal Vein Renin Ratios for Lateralisation and Diagnosis
}

\author{
Martin Wolley Richard D. Gordon Michael Stowasser \\ Endocrine Hypertension Research Centre, University of Queensland School of Medicine, Greenslopes and Princess \\ Alexandra Hospitals, Brisbane, Qld., Australia
}

\section{Key Words}

Secondary hypertension - Reninoma . Renal vein renin ratio

\begin{abstract}
Background/Aim: Reninomas are rare juxtaglomerular tumours which can cause severe hypertension and hypokalaemia. Diagnosis can be problematic and these tumours can be difficult to locate on imaging. In this report we aim to demonstrate the value of carefully performed renal vein renin ratios (RVRRs) to assist in locating these tumours. Method/Results: We report on 3 patients diagnosed with reninoma in our unit. The patients were all female, young (17, 16 and 30 years), severely hypertensive and hypokalaemic (2.5, 2.5 and $3.1 \mathrm{mmol} / \mathrm{l})$. Plasma renin activity (PRA) was elevated $(31.9,274$ and $175 \mathrm{ng} / \mathrm{ml} / \mathrm{h})$, and aldosterone was high-normal (19.9 ng/dl) or elevated (207 and $109.3 \mathrm{ng} / \mathrm{dl}$ ). Renal artery stenosis was excluded by renal artery Doppler, DTPA scan and angiography. Renal CT detected the lesion in 2 patients, with one lesion visible on pre- and post-contrast CT and the other on post-contrast CT only. RVRRs were performed several weeks after withdrawing interfering medications, maintaining a $<40 \mathrm{mmol} /$ day low-sodium diet and maintaining recumbency overnight the night before and during the procedure. Ratios before and after captopril or enalaprilat administration were obtained and lateralised the tumours in all 3 cases (dominant/non-dominant ratios of 2.3,
\end{abstract}

4.3 and 3.8). All of the patients underwent nephrectomy yielding a typical juxtaglomerular tumour and resulting in cure of hypertension and hypokalaemia. Conclusions: Reninoma should be suspected in young hypertensives (especially females) with significant hypokalaemia and high PRA or direct renin concentration after renovascular hypertension has been excluded. CT imaging and carefully performed RVRRs provide the highest likelihood of locating these tumours.

(c) 2013 S. Karger AG, Basel

\section{Introduction}

Reninoma, a renin-secreting tumour of the juxtaglomerular apparatus, is a rare but well-described cause of secondary hypertension [1]. Diagnosis can be very challenging, but once removed, complete and lasting cure of hypertension is likely. Recognition of the tumour by imaging is sometimes difficult due to its small size and lack of enhancement on contrast CT; in such cases, the functional study of renal vein renin ratios (RVRRs) can greatly assist in lateralizing the lesion. This study, however, requires careful preparation to ensure maximal sensitivity [2-4].

We herein report 3 cases of reninoma and the results of diagnostic tests including RVRRs to illustrate the im-

\section{KARGER}

E-Mail karger@karger.com

www.karger.com/ajn (c) 2013 S. Karger AG, Base

0250-8095/13/0391-0016\$38.00/0
Michael Stowasser

Hypertension Unit, University of Queensland School of Medicine Princess Alexandra Hospital

Ipswich Road, Woolloongabba, Brisbane, QLD 4102 (Australia)

E-Mailm.stowasser@uq.edu.au 
Table 1. RVRRs pre- and post-enalaprilat/captopril

\begin{tabular}{|c|c|c|c|}
\hline & Sample & $\begin{array}{l}\mathrm{PRA}, \\
\mathrm{ng} / \mathrm{ml} / \mathrm{h}\end{array}$ & $\begin{array}{l}\text { Ratio, domi- } \\
\text { nant/non- } \\
\text { dominant side }\end{array}$ \\
\hline \multicolumn{4}{|l|}{ Patient 1} \\
\hline Pre-enalaprilat & peripheral & 193 & \\
\hline Pre-enalaprilat & left renal vein & 286 & \\
\hline Pre-enalaprilat & right renal vein & 165 & 1.7 \\
\hline Post-enalaprilat & peripheral & 211 & \\
\hline Post-enalaprilat & left renal vein & 435 & \\
\hline Post-enalaprilat & right renal vein & 187 & 2.3 \\
\hline \multicolumn{4}{|l|}{ Patient 2} \\
\hline Pre-captopril & peripheral & 25 & \\
\hline Pre-captopril & left renal vein & 28 & \\
\hline Pre-captopril & right renal vein & 103 & 3.7 \\
\hline Post-captopril & peripheral & 25 & \\
\hline Post-captopril & left renal vein & 27 & \\
\hline Post-captopril & right renal vein & 116 & 4.3 \\
\hline \multicolumn{4}{|l|}{ Patient 3} \\
\hline Pre-enalaprilat & peripheral & 114 & \\
\hline Pre-enalaprilat & left renal vein & 96 & \\
\hline Pre-enalaprilat & right renal vein & 84 & 1.1 \\
\hline Post-enalaprilat & peripheral & 196 & \\
\hline Post-enalaprilat & left renal vein & 580 & \\
\hline Post-enalaprilat & right renal vein & 153 & 3.8 \\
\hline
\end{tabular}

portant role this investigation played in accurately lateralizing the tumours, especially when other imaging was not conclusive.

\section{Case 1}

A 17-year-old female was referred from another tertiary referral centre for further investigation of recently detected hypertension $(200 / 110 \mathrm{~mm} \mathrm{Hg})$ and hypokalaemia $(2.5 \mathrm{mmol} / \mathrm{l})$, having initially presented with headaches. Serum creatinine was normal and plasma renin activity (PRA) and aldosterone levels after $2 \mathrm{~h}$ of upright posture were measured at $31.9 \mathrm{ng} / \mathrm{ml} / \mathrm{h}$ (upper limit of normal in young women: $10.5 \mathrm{ng} / \mathrm{ml} / \mathrm{h} \mathrm{[5]}$ ) and $19.9 \mathrm{ng} / \mathrm{dl}$ (upper limit of normal in young women: $43.6 \mathrm{ng} / \mathrm{dl}$ [5]), respectively, while taking captopril $12.5 \mathrm{mg}$ twice daily. Intravenous pyelography, renal angiography and renal CT were normal. RVRRs had already been performed elsewhere in the afternoon following morning ambulation while receiving prazosin, methyldopa and having very recently ceased enalapril. The RVRRs did not lateralise renin production (left renal vein: $31 \mathrm{ng} / \mathrm{ml} / \mathrm{h}$, right renal vein: 33 $\mathrm{ng} / \mathrm{ml} / \mathrm{h}$, peripheral vein: $30 \mathrm{ng} / \mathrm{ml} / \mathrm{h}$ ) to either kidney.

On admission to our unit, medications were changed to hydralazine $50 \mathrm{mg}$ twice daily and metoprolol $50 \mathrm{mg}$ twice daily, the latter withheld on the morning of the RVRRs. A strict low-sodium diet $(40 \mathrm{mmol} /$ day) was adhered to for 4 days before the RVRRs were performed in the early morning after overnight recumbency. Under these conditions (a standard, strict protocol at that time for this unit), a significant, lateralising left/right ratio of 1.7 before enalaprilat and 2.3 after it was observed, accompanied by good contralateral suppression, which was defined as the opposite kidney's renal venous renin level being no higher than peripheral (table 1). On careful review of the original CT, a 15-mm non-enhancing lesion, which did not deform the renal surface, was faintly visible in the lower pole of the left kidney in the post-contrast but not the pre-contrast films.

A left nephrectomy was performed revealing a $16-\mathrm{mm}$ wellcircumscribed cortical tumour on sectioning. Histologically, the tumour cells contained abundant granules which, on electron microscopy, were a mixture of mature spherical forms and rhomboidal renin protogranules. Post-operatively, the patient rapidly became normotensive and normokalaemic without medication, and remained so at follow-up 12 years later.

\section{Case 2}

A 16-year-old female was referred for investigation of recently diagnosed severe hypertension on a background of 4 years of migraines and 2 years of episodic epistaxis. She was hypertensive (200/100 mm Hg) despite fosinopril, and hypokalaemic (plasma potassium $2.5 \mathrm{mmol} / \mathrm{l})$ with normal creatinine $(70 \mu \mathrm{mol} / \mathrm{l})$. After $2 \mathrm{~h}$ of upright posture following overnight recumbency, PRA was markedly elevated $(274 \mathrm{ng} / \mathrm{ml} / \mathrm{h})$ and plasma aldosterone was also elevated $(207 \mathrm{ng} / \mathrm{dl})$.

Renal angiography and DTPA isotopic renography were reported as normal. A renal artery duplex scan noted normal renal arteries but an irregular anechoic $11 \times 8 \mathrm{~mm}$ lesion in the lower pole of the right kidney. A CT scan measured the mass at $16 \mathrm{~mm}$, with variable density on pre-contrast study and minimal contrast enhancement. A 6-mm hypo-attenuating lesion was also noted in the left kidney.

In order to avoid interference with interpretation of PRA levels, fosinopril was replaced by hydralazine and slow-release verapamil, and RVRRs were performed after overnight recumbency and 4 days of a 40 -mmol sodium diet, lateralising renin production to the right kidney with a right/left ratio of 3.7 before enalaprilat and $4.3 \mathrm{after}$, with good contralateral suppression (table 1).

A right partial nephrectomy was planned, but due to poor vascular supply of the remaining tissue a total nephrectomy was performed, revealing a 21-mm tumour in the cortex with a cystic component. The main bulk of the tumour was composed of polygonal cells with a granular appearance enhanced by periodic acid-Schiff staining. The hypertension and hypokalaemia resolved after nephrectomy and she remained normotensive and normokalaemic off medications on long-term follow-up.

\section{Case 3}

A 30-year-old female with hypertension diagnosed at age 17 was referred from another tertiary referral centre for hypertension for further investigation because of deteriorating control despite increasing medication. Her blood pressure had previously been well controlled for years on fosinopril and amlodipine, but attempted withdrawal of fosinopril when contemplating pregnancy had led to marked deterioration in blood pressure control which persisted despite reinstating her previous medication regimen. 
Investigations already performed and reported as normal included intravenous pyelography, nuclear medicine renal scan, renal angiography, and pre- and post-contrast CT renal scan. Importantly, RVRRs had been performed at midday after $3 \mathrm{~h}$ of supine posture while taking an unrestricted diet, and were complicated by an asthma attack during the procedure. Left and right renal vein renin levels were 100.8 and $74.8 \mathrm{ng} / \mathrm{ml} / \mathrm{h}$ (left-to-right ratio 1.3 ) before the asthma attack, and rose to $>261$ and $117.1 \mathrm{ng} / \mathrm{ml} / \mathrm{h}$ after it (left-to-right ratio $>2.2$ ), with presumed incomplete contralateral suppression (peripheral PRA not simultaneous, but at the end of the procedure $95.5 \mathrm{ng} / \mathrm{ml} / \mathrm{h}$ ). The stress-related rise in renin release and apparent lack of complete contralateral suppression had been thought to make the results of this study unreliable.

On arrival at our unit, blood pressure was 154/100 whilst taking fosinopril $20 \mathrm{mg}$ daily, verapamil SR $180 \mathrm{mg}$ twice daily, hydralazine $50 \mathrm{mg}$ three times daily, prazosin $5 \mathrm{mg}$ twice daily, lercanidipine $10 \mathrm{mg}$ once daily and clonidine (dose unavailable). Plasma potassium was $3.1 \mathrm{mmol} / \mathrm{l}$ while taking three slow-release potassium chloride tablets per day. Renal function was normal with creatinine $60 \mu \mathrm{mol} / \mathrm{l}$. After withdrawing clonidine and fosinopril and measured after $2 \mathrm{~h}$ upright following overnight recumbency, both PRA (175 ng/ml/h) and plasma aldosterone (109.3 ng/dl) were markedly elevated.

We performed RVRRs according to our strict protocol 2 weeks after fosinopril withdrawal and after 4 days of dietary salt restriction ( $40 \mathrm{mmol} /$ day) and overnight recumbency, and demonstrated lateralisation of stimulated renin production to the left kidney (left-to-right ratio 1.1 before enalaprilat and 3.8 after) with good contralateral suppression (table 1).

Left nephrectomy revealed a 10 -mm well-circumscribed nodular lesion in the lower pole of the left kidney. Histology and electron microscopy findings were consistent with reninoma. Hypertension and hypokalaemia were cured and she remains normotensive on long-term follow-up without antihypertensive medications.

\section{Discussion}

In these 3 patients, RVRRs correctly lateralised the reninomas leading to surgical cure of hypertension and hypokalaemia in all. In 2 of the 3 patients, CT did not unequivocally locate the tumour, and in 2 who had previously undergone RVRRs performed under suboptimal conditions, the results did not clearly indicate which side was dominantly producing renin. This series demonstrates not only the potential value of RVRRs, but also, the great care that must be taken to maximise the sensitivity of the procedure.

Since the first description in 1967 of a patient with severe hypertension resolving following removal of a cortical renal tumour found to contain large amounts of renin [1], reninomas appear to have been rarely reported, with only about 90 cases readily found in the literature $[6,7]$. They are more common in younger patients with most reports in those $<25$ years of age, and there is a female preponderance. They usually present with severe hypertension and biochemical findings such as hypokalaemia consistent with secondary aldosteronism $[6,8]$.

MRI and contrast-enhanced CT are generally able to identify renal tumours accurately, and can be equally effective in the detection of reninomas with rates of detection approaching $100 \%$ in some series $[6,9]$. Small reninomas may be difficult to see, however, and non-reninsecreting lesions may also be observed and be suspected of being reninomas [10]. Notably in this small series, CT failed to detect the tumour in 2 patients before and $1 \mathrm{pa}-$ tient after contrast, and also reported bilateral lesions in 1 patient.

RVRRs are a valuable tool to assess the functional status of suspected reninomas and assist in locating these tumours. However, variable success of this investigation in achieving accurate lateralisation of the reninoma has been reported. Haab et al. [8] reported that 3 of 8 patients with reninoma were unable to be lateralised by RVRR despite repeated attempts and despite all having lesions visible on CT. In an analysis of 50 case reports, Wong et al. [6] suggested that using a 'lateralisation ratio' of renin levels between the renal veins of 1.5 (the cutoff value typically interpreted as significant in the setting of suspected renovascular hypertension [11]) gave a sensitivity of 56\% and specificity of $94 \%$ for confirming the correct side of a reninoma. Precise details of patient preparation were not described for either of these case series.

Renin release shows diurnal variability, and is markedly responsive to postural changes, sodium intake, catecholamines and many drugs [12-14]. Sodium restriction improves the sensitivity of RVRRs in diagnosing renovascular hypertension, and as renin release from reninomas can retain responsiveness to sodium, reduction of sodium intake may also be necessary to maximise the sensitivity of the test to detect reninomas.

Our protocol for this procedure entails cessation of potentially interfering medications (including diuretics, beta blockers, angiotensin-converting enzyme inhibitors and angiotensin II receptor blockers) where possible at least 4 weeks before the test. The patients are then admitted to hospital several days prior to the test to administer a low-sodium diet $(<40 \mathrm{mmol} /$ day $)$ and provide relaxation training to minimise the chance of stress-related renin fluctuations before or during the procedure. Overnight recumbent and 2-hour upright samples are collected on the third morning of the low-sodium diet to observe the response to upright posture and the level of peripheral blood renin in the recumbent position, which in-
18

Am J Nephrol 2014;39:16-19 DOI: $10.1159 / 000357410$
Wolley/Gordon/Stowasser 
forms the laboratory of any need for dilution of plasma samples before assay in the case of very high renin levels, and the length of incubation time required in the PRA assay in the case of low renin levels. Twenty-four-hour urine samples are collected for measurement of sodium excretion on admission and on the penultimate day in order to check adherence to the low-salt diet. Patients maintain the supine position overnight the night before and throughout the early morning RVRR procedure. Using two catheters introduced through one femoral vein, samples are collected simultaneously from each renal vein and from a peripheral vein before, and then $15 \mathrm{~min}$ after, the administration of a rapidly acting angiotensinconverting enzyme inhibitor (intravenous enalaprilat $0.04 \mathrm{mg} / \mathrm{kg}$ to maximum of $2.5 \mathrm{mg}$ or oral captopril 25 $\mathrm{mg}$ ). This stimulates renin release so that samples are collected during active renin secretion and not during a quiescent phase [15], improving the sensitivity of the test [16, 17]. Speculation that some tumours drain to pericapsular veins has been thought to explain why RVRRs sometimes fail to lateralise reninomas [8], but not sampling during active secretion may have been the explanation. As can be seen from the marked improvement in lateralisation in the cases described here, when the test is performed in optimal versus sub-optimal conditions, an unhelpful test can become diagnostic. Careful patient preparation and controlled conditions of sampling appear to be the most important elements.

Partial nephrectomy is the favoured treatment for reninoma, with excellent reported outcomes $[6,8]$. However, other authors have recommended total nephrecto$\mathrm{my}$, as it is a more straightforward procedure with a lower incidence of complications. It is certainly the treatment of choice where imaging studies have failed to identify beyond reasonable doubt the precise intrarenal location of the reninoma. Medical treatment with angiotensinconverting enzyme inhibitors or direct renin blockers might be successful in controlling hypertension and hypokalaemia for at least some time, but evolution to refractory hypertension appears to be common with increasing duration of disease $[6,18]$ - whether or not these medications could prevent this is unknown.

In summary, reninomas are a rare but curable form of hypertension which can present diagnostic challenges. As shown in this case series, they can be correctly located with careful study of RVRRs, even when the lesion is not visible on other imaging studies.

\section{Disclosure Statement}

The authors have no conflicts of interest to report.

\section{References}

1 Robertson PW, Klidjian A, Harding LK, Walters G, Lee MR, Robb-Smith AH: Hypertension due to a renin-secreting renal tumour. Am J Med 1967;43:963-976.

2 Gordon R: The causes of secondary hypertension: investigational methods and indications; in Sleight P, Vann Jones J (eds): Scientific Foundation of Cardiology. London, William Heinemann, 1983, pp 165-178.

-3 Gordon RD, Tunny TJ, Evans EB, Fisher PM, Jackson RV: Unstimulated renal venous renin ratio predicts improvement in hypertension following nephrectomy for unilateral renal disease. Nephron 1986;44(Suppl 1):25-28.

-4 Pimenta E, Gordon RD, Daunt N, Slater G, Stowasser M, Medscape: Hyperreninemic hypertension following presumed abdominal trauma. Nat Rev Nephrol 2011;7:730-734.

5 Sequeira SJ, Loughlin T, Cunningham S, Culliton MT, Hannon S, Heffernan A, et al: Evaluation of an aldosterone radioimmunoassay: the renin-angiotensin-aldosterone axis as a function of sex and age. Ann Clin Biochem 1986;23:65-75

6 Wong L, Hsu TH, Perlroth MG, Hofmann LV, Haynes CM, Katznelson L: Reninoma: case report and literature review. J Hypertens 2008;26:368-373.

-7 Gottardo F, Cesari M, Morra A, Gardiman M, Fassina A, Dal Bianco M: A kidney tumor in an adolescent with severe hypertension and hypokalemia: an uncommon case - case report and review of the literature on reninoma. Urol Int 2010;85:121-124.

8 Haab F, Duclos JM, Guyenne T, Plouin PF, Corvol P: Renin secreting tumors: diagnosis, conservative surgical approach and longterm results. J Urol 1995;153:1781-1784.

$\checkmark 9$ Kang SK, Chandarana H: Contemporary imaging of the renal mass. Urol Clin North Am 2012;39:161-170, vi.

10 Dong D, Li H, Yan W, Xu W: Juxtaglomerular cell tumor of the kidney - a new classification scheme. Urol Oncol 2010;28:34-38.

11 Rossi GP, Cesari M, Chiesura-Corona M, Miotto D, Semplicini A, Pessina AC: Renal vein renin measurements accurately identify renovascular hypertension caused by total occlusion of the renal artery. J Hypertens 2002;20:975-984.

$\checkmark 12$ Gordon RD, Wolfe LK, Island DP, Liddle GW: A diurnal rhythm in plasma renin activity in man. J Clin Invest 1966;45:1587-1592.
13 Toffelmire EB, Slater K, Corvol P, Menard J, Schambelan M: Response of plasma prorenin and active renin to chronic and acute alterations of renin secretion in normal humans. Studies using a direct immunoradiometric assay. J Clin Invest 1989;83:679-687.

14 Kopp U, DiBona GF: Interaction of renal beta 1 -adrenoceptors and prostaglandins in reflex renin release. Am J Physiol 1983;244:F418F424.

15 Tunny TJ, Klemm SA, Hamlet SM, Gordon $\mathrm{RD}$ : Diagnosis of unilateral renovascular hypertension: comparative effect of intravenous enalaprilat and oral captopril. J Urol 1988; 140:713-715.

16 Simon G, Coleman CC: Captopril-stimulated renal vein renin measurements in the diagnosis of atherosclerotic renovascular hypertension. Am J Hypertens 1994;7:1-6.

17 Tomoda F, Takata M, Ohashi S, Ueno H, Ikeda K, Yasumoto K, et al: Captopril-stimulated renal vein renin in hypertensive patients with or without renal artery stenosis. Am J Hypertens 1990;3:918-926.

18 Chao CT, Wu VC: Aliskiren for reninoma. Nephrology (Carlton) 2012;17:308-309. 